\section{Mustard Seed Meal for Management of Root-knot Nematode and Weeds in Tomato Production}

\author{
Susan L.F. Meyer ${ }^{1,7}$, Inga A. Zasada ${ }^{2}$, Shannon M. Rupprecht ${ }^{1}$, \\ Mark J. VanGessel ${ }^{3}$, Cerruti R.R. Hooks ${ }^{4}$, Matthew J. Morra ${ }^{5}$, \\ and Kathryne L. Everts ${ }^{6}$
}

\begin{abstract}
ADDITIONAL INDEX wORDs. amendment, biofuel by-products, Brassica, glucosinolate, Meloidogyne incognita, phytotoxicity, plant disease, soilborne plant-pathogenic fungi, Sinapis
\end{abstract}

Summary. Mustard seed meals of indian mustard [InM (Brassica juncea)] and yellow mustard [YeM (Sinapis alba)], alone and combined, were tested for effects on tomato (Solanum lycopersicum) plants and for suppression of southern root-knot nematode [RKN (Meloidogyne incognita)] and weed populations. In the greenhouse, with all seed meal treatments applied at $0.25 \%$ total $\mathrm{w} / \mathrm{w}$ soil, low tomato plant stands (up to $60 \%$ dying/dead) resulted from amendment with 3 YeM: 1 InM, 1 YeM:I InM, and YeM, applied right before transplant. Compared with untreated controls, low numbers of RKN eggs per gram root were consistently recorded from amendment with 3 YeM:1 InM. In a 2012 field study, incorporation of 1 YeM:1 InM (1700 lb/acre) resulted in lower tomato root biomass than fertilizer application (504 lb/acre), YeM or InM (each $1700 \mathrm{lb} / \mathrm{acre})$. All treatments were applied with added fertilizer to achieve 100-102 lb/acre nitrogen, $7.4 \mathrm{lb} /$ acre phosphorus, $74.7 \mathrm{lb} /$ acre potassium, $6.0 \mathrm{lb} /$ acre sulfur, and $1.0 \mathrm{lb} /$ acre boron. The lowest numbers of RKN eggs per gram root (harvest 2012) were collected from plots amended with InM (1700 lb/acre), YeM (850 lb/acre), and 3 YeM:1 InM $(1700 \mathrm{lb} /$ acre $)$, but the numbers were not significantly different from fertilizer only (504 lb/acre) controls. Highest and lowest tomato yields (numbers of fruit) in 2012 were recorded from YeM $(850 \mathrm{lb} / \mathrm{acre})$ and $3 \mathrm{YeM}: 1 \mathrm{InM}(1700 \mathrm{lb} / \mathrm{acre})$ amendments, respectively. In 2013, there were no significant differences among treatments in eggs per gram root or in tomato yields. No mustard seed meal treatment affected weed populations. At the tested rates, YeM seed meal showed potential for use in tomato beds but results were inconsistent between years.

$\mathrm{D}$ eregistration of synthetic chemical pesticides has increased the need for alternative management strategies directed at soilborne diseases and pests. One alternative available to conventional and organic growers is incorporation of mustard seed meal amendments into soil. Agricultural use of these meals, which are by-products of biodiesel fuel production from brassicaceous plants, has the added advantage of contributing to increased profitability of producing biofuel from oilseeds. Mustard seed meals can be amended into soil as fertilizers, for suppression of soilborne pests and pathogens (Brown and Morra, 2005; Gigot et al., 2013; Mazzola et al., 2007; Meyer et al., 2011; Zasada et al., 2009) and for weed management (Brown and Morra, 2005; Hansson et al., 2008; Rothlisberger et al., 2012; Vaughn et al., 2006).

Root-knot nematodes (Meloidogyne sp.) are among the pathogens that can be suppressed by incorporation of mustard seed meals into soil. Application of ethiopian mustard (Brassica carinata) at a rate of $2.5 \mathrm{t} \cdot \mathrm{ha}^{-1} \mathrm{de}-$ creased numbers of columbia RKN (Meloidogyne chitwoodi) on potato (Solanum tuberosum) and increased tuber yields in field plots (Henderson et al., 2009). When applied to soil in greenhouse pots at $0.52 \%(2.6 \mathrm{~g}$ per $500 \mathrm{~g}$ sand/soil), this seed meal also reduced numbers of columbia
RKN on tomato (Henderson et al., 2009). Populations of javanese RKN (Meloidogyne javanica) were suppressed in vineyards when InM seed meal was applied at $2 \mathrm{t} \cdot \mathrm{ha}^{-1}$ (Rahman and Somers, 2005). Defatted seed meals from Brassicaceae seeds, with sinigrin as the main glucosinolate, were applied to soil at $3 \mathrm{t} \cdot \mathrm{ha}^{-1}$ and reduced RKN populations on zucchini [Cucurbita pepo var. cylindrica (Lazzeri et al., 2009)]. In laboratory experiments, seed meals of InM, YeM, and rapeseed (Brassica napus) were applied at rates of $0.05 \%$ to $10.0 \%(\mathrm{w} / \mathrm{w})$; at the higher application rates, each meal reduced recovery of RKN from baermann funnels (Zasada et al., 2009). The greatest activity against nematodes in this study resulted from applications of InM seed meal. In greenhouse studies on pepper (Capsicum annuum) plants, InM and YeM seed meals were applied to soil at rates of $0.05 \%$ to $0.2 \%$ $(\mathrm{w} / \mathrm{w})$. At most of the tested application rates, amendment with InM tended to result in lower RKN numbers on pepper roots than amendment with YeM, although differences were not always significant (Meyer et al., 2011).

In addition to individual seed meals, combinations have been tested for suppression of RKN and other pathogens, because the mixture of two plant chemistries increases the types of active chemicals amended into the soil. For example, a combination of 1 YeM:3 InM was less toxic to greenhouse-grown pepper than YeM applied alone and as effective against RKN (Meyer et al., 2011). Disease control and apple (Malus domestica) yields were enhanced with application of an InM/rapeseed mixture, with results dependent on apple cultivar (Mazzola et al., 2007; Mazzola and

\begin{tabular}{llll}
\hline $\begin{array}{l}\text { Units } \\
\begin{array}{l}\text { To convert U.S. to SI, } \\
\text { multiply by }\end{array}\end{array}$ & U.S. unit & SI unit & $\begin{array}{l}\text { To convert SI to U.S., } \\
\text { multiply by }\end{array}$ \\
\hline 29.5735 & $\mathrm{fl} \mathrm{oz}$ & $\mathrm{mL}$ & 0.0338 \\
0.3048 & $\mathrm{ft}$ & $\mathrm{m}$ & 3.2808 \\
0.0929 & $\mathrm{ft}^{2}$ & $\mathrm{~m}^{2}$ & 10.7639 \\
2.54 & inch $(\mathrm{es})$ & $\mathrm{cm}$ & 0.3937 \\
25.4 & inch $(\mathrm{es})$ & $\mathrm{mm}$ & 0.0394 \\
0.4536 & $\mathrm{lb}$ & $\mathrm{kg}$ & 2.2046 \\
1.1209 & $\mathrm{lb} / \mathrm{acre}$ & $\mathrm{kg} \cdot \mathrm{ha}^{-1}$ & 0.8922 \\
1 & micron $(\mathrm{s})$ & $\mu \mathrm{m}$ & 1 \\
28.3495 & $\mathrm{oz}$ & $\mathrm{g}$ & 0.0353 \\
2.2417 & ton $(\mathrm{s}) / \mathrm{acre}$ & $\mathrm{t} \cdot \mathrm{ha}^{-1}$ & 0.4461 \\
$\left({ }^{\circ} \mathrm{F}-32\right) \div 1.8$ & ${ }^{\circ} \mathrm{F}$ & ${ }^{\circ} \mathrm{C}$ & $\left({ }^{\circ} \mathrm{C} \times 1.8\right)+32$
\end{tabular}


Brown, 2010; Mazzola and Straus, 2014).

While application of mustard seed meals to soil may be beneficial for suppression of plant pathogens, the amendments can also be detrimental to cash crops. For example, lettuce (Lactuca sativa), carrot (Daucus carota), cotton (Gossypium hirsutum), and beet (Beta vulgaris) germination or seedling emergence have been suppressed by application of YeM, InM, or rapeseed meals in some studies, although results depend on multiple factors, including timing and rates of application (Meyer et al., 2011; Rothlisberger et al., 2012; Snyder et al., 2009). Because of potential phytotoxicity, application of mustard seed meals as biofumigants must be timed to avoid phytotoxicity to crop plants.

Influenced by these findings, we investigated impacts of individual and combined InM and YeM seed meal amendments on tomato fruit yield and diseases. Greenhouse tests were performed to investigate length of time needed between mustard seed meal amendment and tomato seedling transplant to avoid phytotoxicity to the seedlings. We also conducted

We thank David Armentrout, Raymond Moore, Mason Newark, Rachel Jones, Lashaun Caesar, Daniel Mongeon, Prasanti Babu, Margaret MacDonald, Paroo Chauhan, and Kate Weiss for assistance in the laboratory, greenhouse and field. We also thank Bryan Vinyard (USDA ARS Biometrical Consulting Service, Beltsville, MD) for statistical analyses of the phytotoxicity trials.

Mention of trade names or commercial products in this publication is solely for the purpose of providing specific information and does not imply recommendation or endorsement by the U.S. Department of Agriculture.

${ }^{1}$ USDA-ARS, Nematology Laboratory, Henry A. Wallace Beltsville Agricultural Research Center (BARC)-West, Building 010A, Room 112, 10300 Baltimore Avenue, Beltsville, MD 20705

${ }^{2}$ USDA-ARS Horticultural Crops Research Laboratory, 3420 NW Orchard Avenue, Corvallis, OR 97330

${ }^{3}$ College of Agriculture and Natural Resources, University of Delaware Research and Education Center, 16483 County Seat Highway, Georgetown, DE 19947

${ }^{4}$ Department of Entomology, 4112 Plant Sciences Building, University of Maryland, College Park, MD 20742

${ }^{5}$ Division of Soil and Land Resources, University of Idaho, 875 Perimeter Drive MS 2339, Moscow, ID 83844

${ }^{6}$ Department of Plant Science and Landscape Architecture, University of Maryland, Lower Eastern Shore Research and Education Center, 27664 Nanticoke Road, Salisbury, MD 21801

${ }^{7}$ Corresponding author. E-mail: Susan.L.Meyer@ars. usda.gov. studies to determine seed meal effects on tomato plant vigor and suppression of nematode populations in greenhouse-grown plants. The third phase of the research was to study mustard seed meal potential for improving tomato yield, and suppressing plant-parasitic nematode, plant disease and weed populations in fieldgrown tomato.

\section{Materials and methods}

SOUTHERN RKN INOCULUM AND TOMATO CULTIVAR. An isolate of RKN Race 1, originally collected in Maryland, was grown on 'PA-136' pepper in greenhouse pots. Eggs for greenhouse experiments were obtained from $\approx 3$-month-old plants following procedures in Meyer et al. (2011). 'BHN 444' tomato was used for all greenhouse and field trials.

SEED MEALS AND SOIL ANALYSIS. The mustard seed meals tested were 'Pacific Gold' InM and 'Ida Gold' YeM (Farm Fuel, Freedom, CA), purchased as flake formulations. Linseed (Linum usitatissimum) meal, which does not contain glucosinolate, was used as a control in the greenhouse studies. Mustard seed meal flake sizes ranged from $\approx 0.8$ to $10 \mathrm{~mm}$ diameter. In addition, InM seed meal flakes were finely ground with a mortar and pestle and applied as an additional treatment in the 2013 field study; the flakes were $<5 \mathrm{~mm}$ diameter. Linseed meal flake sizes ranged from $\approx 0.07$ to $1.5 \mathrm{~mm}$ diameter. Meals were analyzed for sinigrin and sinalbin content following the methods in Popova and Morra (2014). For the greenhouse studies, glucosinolate content was $132 \mu \mathrm{mol} \cdot \mathrm{g}^{-1}$ meal for $\mathrm{YeM}$ and $149 \mu \mathrm{mol} \cdot \mathrm{g}^{-1}$ meal for InM (total meal basis). Mustard seed meals were ordered fresh each year of the field trials. Glucosinolate content for InM was $154 \mu \mathrm{mol} \cdot \mathrm{g}^{-1}$ meal in 2012 , and $153 \mu \mathrm{mol} \cdot \mathrm{g}^{-1}$ meal in 2013. For YeM, glucosinate values were $118 \mu \mathrm{mol} \cdot \mathrm{g}^{-1}$ meal in 2012 , and $124 \mu \mathrm{mol} \cdot \mathrm{g}^{-1}$ meal in 2013. Percent nitrogen (N), phosphorus $(\mathrm{P})$, and potassium $(\mathrm{K})$ content was similar among all three meals (5.7\% to $6.1 \% \mathrm{~N}, 1.0 \%$ to $1.3 \% \mathrm{P}$, $1.2 \%$ to $1.4 \% \mathrm{~K})$.

All field experiments were conducted at the Lower Eastern Shore Research and Education Center (LESREC) in Salisbury, MD, and soil for the greenhouse studies was collected there as well. The soil type in the field used in 2012 was classified as sandy loam $(78.4 \%$ sand, $12.8 \%$ silt, $8.8 \%$ clay; $1.4 \%$ organic matter, soil $\mathrm{pH}$ 6.7), and the field in 2013 as Fort Mott loamy sand $(88.4 \%$ sand, $4.8 \%$ silt, $6.8 \%$ clay; organic matter $1.3 \%$, soil $\mathrm{pH}$ 6.7). Greenhouse trials were conducted with the sandy loam collected from the site of the 2012 field study.

Phytotoxicity of MUSTARD SEED MEALS IN THE GREENHOUSE. Methods for this study were similar to those described in Meyer et al. (2011). Soil was amended with treatments $(400 \mathrm{~g}$ soil + amendment per bag) or left untreated, $48 \mathrm{~mL}$ water $(\approx 70 \%$ water holding capacity of the soil) was added to each bag, and the soils ( \pm amendment) were placed into 4-inch-diameter pots at six l-week intervals: the day of tomato seedling transplant (Week 0), and at 1, 2, 3, 4, and 5 weeks before transplant. Treatments were 1) 0.19\% YeM:0.06\% InM (3 YeM:1 InM); 2) 0.125\% YeM:0.125\% InM (1 YeM:1 InM); 3) $0.06 \%$ YeM:0.19\% InM (1 YeM:3 InM); 4) $0.25 \%$ YeM; 5$)$ 0.25\% InM; 6) $0.25 \%$ linseed meal control, tarp; 7) $0.25 \%$ linseed meal control, no tarp; 8) untreated, tarp control; and 9) untreated, no tarp control. Total percent of all seed meal treatments was $0.25 \%$ weight amendment/weight dry soil. All mustard seed meal treatments were covered with a black plastic tarp. The pots were arranged in a randomized complete block design. Pots were initially hand watered one to two times per day. Starting Week 2 of Trial 1 , and continuing throughout Trial 2, a drip irrigation system was used to water each pot. On the day that the Week 0 treatments were placed into pots, a 33- to 34-d-old tomato seedling, started in growing medium (Promix; Premier Horticulture, Quakertown, PA), was transplanted into each pot. The greenhouse was maintained at 24 to $29{ }^{\circ} \mathrm{C}$, with natural and supplemental lighting combined for a 16-h daylength. The plants were harvested 2 weeks after transplant to determine if there was initial phytotoxicity to young seedlings. Shoot lengths (from soil to growing tip), shoot fresh weights, shoot dry weights, root fresh weights, and number of viable plants in each pot were recorded. The experiment was conducted twice, with five replicate tomato seedlings per seed meal 
treatment/application time in each of the two trials $(N=10)$.

SuPPRESSION OF SOUTHERN RKN POPULATIONS IN THE GREENHOUSE. Treatments with RKN were 1) untreated, no tarp control; 2) untreated, tarp control; 3) $0.25 \%$ linseed meal, no tarp control; 4) $0.25 \%$ linseed meal, tarp control; 5) $0.25 \%$ YeM; 6) $0.25 \%$ InM; 7) 0.19\% YeM:0.06\% InM (3 YeM:1 InM); 8) 0.125\% YeM:0.125\% InM (1 YeM:1 InM); and 9) $0.06 \%$ YeM:0.19\% InM (1 YeM:3 InM). Control treatments without RKN were 10) untreated, no tarp; 11) untreated, tarp; 12) $0.25 \%$ linseed meal, no tarp; and 13) $0.25 \%$ linseed meal, tarp. Total percentage of all seed meal treatments was $0.25 \%$ weight amendment/weight dry soil. All mustard seed meal treatments were tarped.

Procedures and conditions were as described above for phytotoxicity trials, except that some treatments received $5000 \mathrm{RKN}$ eggs in $5 \mathrm{~mL}$ water $+43 \mathrm{~mL}$ water per bag; soil without $\mathrm{RKN}$ received $48 \mathrm{~mL}$ water. Pots were arranged in a randomized complete block design. A drip irrigation system was used to water each pot, and 2 weeks after nematode inoculation, one tomato seedling $(\approx 5$ weeks old) was transplanted into each pot. Plants were fertilized as needed with $15 \mathrm{~N}-3.9 \mathrm{P}-10 \mathrm{~K}$ controlledrelease fertilizer (Osmocote 15-9-12; Scotts-Sierra Horticultural Products; Marysville, $\mathrm{OH}$ ). Five weeks later, numbers of eggs and second-stage juveniles (J2), shoot lengths, shoot fresh weights, and root fresh weights were recorded. Root galling index values were $0=$ no galls, $1=$ less than 5 galls, $5=5$ to 25 galls, $10=26$ to 100 galls, and $25=$ more than 100 galls (Daulton and Nusbaum, 1961). For nematode counts, roots were processed as described in Meyer et al. (2011): the roots were washed free of soil, cut, blended in $0.6 \%$ sodium hypochlorite for $1 \mathrm{~min}$, rinsed over nested 250 and $25-\mu \mathrm{m}$-mesh sieves, and the eggs and $\mathrm{J} 2$ collected on the $25-\mu \mathrm{m}$-mesh sieve. The experiment was conducted twice, with eight replicate pots per treatment in each trial $(N=16)$.

Field Studies, General PROCEDURES FOR 2012 AND 2013. Field trials were conducted in 2012 and 2013 at the University of Maryland's LESREC. Procedures common to both years are described in this section; variations particular to each year are described below under "Field Trial 2012" and "Field Trial 2013." The field used in 2013 was naturally infested, but both fields were inoculated with RKN, as described below for each year.

Field treatments were 1) fertilizer only, $504 \mathrm{lb} /$ acre; 2) YeM high rate, $1700 \mathrm{lb} / \mathrm{acre}$; 3$)$ InM high rate, $1700 \mathrm{lb} / \mathrm{acre}$; 4) YeM low rate, 850 $\mathrm{lb} / \mathrm{acre} ; 5$ ) InM low rate, $850 \mathrm{lb} / \mathrm{acre}$; 6) $3 \mathrm{YeM}: 1 \mathrm{InM}$, high rate, $1700 \mathrm{lb} /$ acre combined; 7) 1 YeM:1 InM, high rate, $1700 \mathrm{lb} /$ acre combined; 8) 1 YeM:3 InM, high rate, $1700 \mathrm{lb} /$ acre combined; and 9) InM high rate, 1700 $\mathrm{lb} / \mathrm{acre}$, finely ground (2013 only). All treatments were adjusted with added fertilizer to achieve 100 to $102 \mathrm{lb} /$ acre $\mathrm{N}, 7.4 \mathrm{lb} /$ acre P, $74.7 \mathrm{lb} /$ acre K, 6.0 $\mathrm{lb} /$ acre sulfur $(S)$ and $1.0 \mathrm{lb} / \mathrm{acre}$ boron (B).

The two trials were conducted as randomized complete-block designs with five blocks per $130 \mathrm{ft}$ row, and eight (2012) or nine (2013) treatments per block, for a total of 40 (2012) or 45 (2013) plots. Plots were $20 \mathrm{ft} \times 28$ inches, with $5 \mathrm{ft}$ between plots. As with greenhouse experiments, tomato seeds were started in Premier Promix. The seedlings were maintained in a greenhouse for $\approx 6$ weeks, moved outside, and then 7-week-old seedlings were transplanted into raised beds covered with black plastic and drip irrigation, with a single row of tomato seedlings, 24 inches apart in each row. Throughout the summer, plots were irrigated as needed. To sample for RKN J2 in the soil, six soil samples ( 1 inch diameter $\times 8$ inches deep) were randomly collected from each plot and bulked, and $\mathrm{J} 2$ were extracted from soil using the baermann funnel method for $5 \mathrm{~d}$ (Hooper, 1986). Twice each year, root systems were harvested from each plot; one at midseason and three at harvest. Root weights were recorded, and eggs collected and enumerated. Plant heights and weights (three plants per plot) were recorded in 2013. Tomato fruit was weighed and graded at three harvests in 2012 and six harvests in 2013.

Field trIAL 2012. This field was not naturally infested with RKN, so cucumber roots inoculated with RKN were transplanted into the field in
Spring 2011, followed later in the season by susceptible soybean. In Oct. 2011 , soybean roots were sampled; J2 were present but in very low numbers. Consequently, tomato seedlings $(6.5$ weeks old), each inoculated with 5000 RKN eggs, were transplanted into the field on 17 May 2012. These tomato plants were rototilled into the soil on 19 June 2012. On 20 June 2012, mustard seed meal and control treatments (see above) were spread by hand onto the plots that had contained the inoculated tomato plants, and the treatments were incorporated as the beds were made and the black plastic tarp was laid over the rows. Transplant holes (24 inches apart) were made in the tarp. RKN eggs, 5000 in $5 \mathrm{~mL}$ water, were added to each hole, and the holes were taped shut. Two weeks later (5 July 2012), a 7-week-old tomato seedling was transplanted into each inoculated hole. Excessive heat the day of transplant resulted in some plant death, so $6 \mathrm{~d}$ after transplant, replacement seedlings were transplanted into those planting holes. On 14 Aug. 2012, midseason root samples (one tomato root system per plot) were collected. For egg extraction in 2012, roots were washed and cut, covered with $0.6 \%$ sodium hypochlorite in a container, and placed on a shaker for $3 \mathrm{~min}$ at maximum speed. The contents of the container were poured over nested 180 and $25-\mu \mathrm{m}$-mesh sieves, and eggs were retained on the $25-\mu \mathrm{m}$-mesh sieve. Root weights were determined fresh (Aug. 2012) or dry (Oct. 2012); washed roots retained on the 180 $\mu \mathrm{m}$-mesh sieve were placed in a $70{ }^{\circ} \mathrm{C}$ oven for 1 week before determining dry weight. Due to the late transplant date compared with mid-Atlantic production fields, fruit matured late in the season, and the harvest period was compressed. Tomato fruit were therefore weighed and graded on 1 , 5 , and 9 Oct. 2012. Harvest root and soil samples (three root samples per plot) were collected on 10 Oct. 2012 and processed as described above and in the general procedures for field studies.

Field trial 2013. In 2013, a field naturally infested with RKN was used for the study. Crimson clover (Trifolium incarnatum) was grown in the field over the winter (2012-13) to maintain nematode populations. Soil samples for nematode 
counts were collected on 14 May 2013, and treatments applied on 15 May 2013. Three of the five replicate sets of treatment plots were inoculated with additional nematodes after plastic tarps were laid, as described above. Two weeks later (30 May 2013), tomato seedlings ( 7 weeks old) were transplanted into the field. Soil and root samples (one root system per plot) were collected on 17 July 2013. Tomato fruit were weighed and graded on six dates: $2,8,15,21$, and 27 Aug. and 3 Sept. 2013. Aboveground plant heights and weights were collected on 3 Sept. 2013. Roots (three root systems per plot) and soil samples were collected on 4 and 5 Sept. 2013. Root systems were washed, frozen, and after thawing processed by a method similar to that used for the greenhouse studies.

WEED POPULATIONS AND FUNGAL AND BACTERIAL PLANT DISEASES IN THE FIELD. After black plastic was laid in 2012 , a $1-\mathrm{ft}^{2}$ section of the plastic was removed and 50 seeds of smooth pigweed (Amaranthus bybridus), jimsonweed (Datura stramonium), pitted morning glory (Ipomoea lacunosa), large crabgrass (Digitaria sanquinalis), and giant foxtail (Setaria faberi) were spread on the soil surface, and then lightly pressed into the soil. A thin layer of sterilized field soil was then spread over the section. The black plastic was laid back in place and the edges sealed with duct tape. At the time of tomato planting, the $1-\mathrm{ft}^{2}$ section of black plastic was removed. Weeds were counted by species on 2 and 16 Aug. 2012. In addition to the species seeded, carpetweed (Mollugo verticillata) and annual spurges (Euphorbia species) were present. In 2013, the seedbank was not supplemented with weed seeds, and the $1-\mathrm{ft}^{2}$ section of black plastic was removed at the time of tomato planting. Weeds were counted on 19 June, 9 July, and 8 Aug. Prickly sida (Sida spinosa) was the only species observed in 2013 but was not present in 2012 .

In 2012 and 2013, tomato plants were observed weekly for incidence and severity of foliar diseases including septoria leaf spot (Septoria lycopersici), bacterial spot (Xanthomonas campestris pv. vesicatoria), and early blight (Alternaria solani).

Statistical methods. For the tomato seedling phytotoxicity study, each of the 54 combinations (nine seed meal treatments and six application times to soil) was applied to five plants in each of two trials in the greenhouse. Pairwise comparison of the 54 treatment $\times$ week combinations was accomplished using a oneway analysis of variance (ANOVA) with the Sidak adjustment to maintain an overall $\alpha=0.05$. Trial was included in the ANOVA model as a fixed effect, to adjust for any overall trial difference. For shoot fresh weight, root fresh weight, and shoot length, variance groups were specified to model the differently sized (i.e., heterogeneous) within treatment and week variances. Statistical analyses were conducted using PROC GLIMMIX in SAS (version 9.4; SAS Institute, Cary, $\mathrm{NC})$.

To determine effects of the seed meals on tomato plants and suppression of RKN population numbers in the greenhouse, data analyzed were tomato shoot lengths, shoot and root fresh weights, root gall indices, and number of RKN eggs per gram root. Root galling indices and numbers of RKN eggs per gram root on tomato plants were $\log _{10}(x+1)$-transformed before analysis. From the field trials, data analyzed were J2 per $100 \mathrm{~g}$ soil, eggs per gram root, plant heights, plant weights, root fresh weights, tomato fruit numbers, and tomato fruit weights. The $2012 \mathrm{~J} 2$ per $100 \mathrm{~g}$ soil, 2012 eggs per gram root, 2013 midseason eggs per gram root, Sept. 2013 root fresh weights, 2012 fruit weights, and 2013 harvest plant heights were $\log _{10}(x+1)$-transformed before analysis. Data from these greenhouse and field studies were analyzed with the statistical package JMP 11.2.0 (SAS Institute). Differences among treatments were determined by ANOVA, and means were compared using Tukey-Kramer's adjustment for multiple comparisons $(P \leq 0.05)$. Data presented are nontransformed means. Weed analysis was conducted with number of weeds summed during the growing season $(P \leq 0.05)$. Before analysis, weed counts were transformed by $\log (\mathrm{x}+$ 0.1). Data presented are nontransformed means.

\section{Results}

Phytotoxicity of MUSTaRd SEED MEALS IN THE GREENHOUSE. TOmato seedling survival was $100 \%$ in most of the mustard seed meal/time combinations. Dying (wilting and yellowing) or dead plants were observed in some pots when the tomato seedlings had been transplanted at Weeks 0 or 1 . Treatments affecting plant stand at Week 0 were 3 YeM:1 InM ( $60 \%$ of plants dying), 1 YeM:1 InM ( $40 \%$ of plants dying), YeM (40\% of plants dying, $10 \%$ dead), and linseed meal, no tarp (20\% dead or dying). Treatments affecting plant stand at Week 1 were YeM (11\% dying) and untreated soil with tarp (10\% dying).

Shoot lengths and weights (data not shown) were recorded from all plants except those that had died, and were generally not different among treatments, with a few exceptions. Overall, the shortest and lightest shoots were recorded Week 0 , from two treatments that contained YeM. Those treatments were 3 YeM: 1 InM and 1 YeM:1 InM. YeM seed meal was no longer phytotoxic to tomato seedlings within 2 weeks of amendment. Root fresh weights demonstrated similar results in that lighter roots were recorded with higher YeM-containing treatments applied close to transplant (Fig. 1). Root fresh weights were lowest when these seed meals were applied at Week 0 , and when YeM was applied 1 week before transplant. However, at Week 0, only the untreated soil with tarp resulted in significantly greater root weights. No treatments applied at Weeks 1-5 were significantly different from other treatments applied within those weeks.

SUPPRESSION OF SOUTHERN RKN POPULATIONS IN THE GREENHOUSE. Effects of seed meals on tomato shoot length and fresh weight differed between greenhouse trials in the study with RKN (Table 1). In Trial 1, the longest shoots were recorded from plants grown in tarped pots containing untreated soil inoculated with nematodes, and the shortest shoots $(39.5 \%$ shorter $)$ from plants grown in pots with no tarp, untreated soil, and no nematodes. Shoots in pots with no tarp, untreated soil, and nematodes were also smaller; $22.5 \%$ shorter than the longest shoots. When the soil was amended with linseed meal, there was no difference in shoot lengths between plants grown in soil with or without tarp, indicating that the linseed meal 


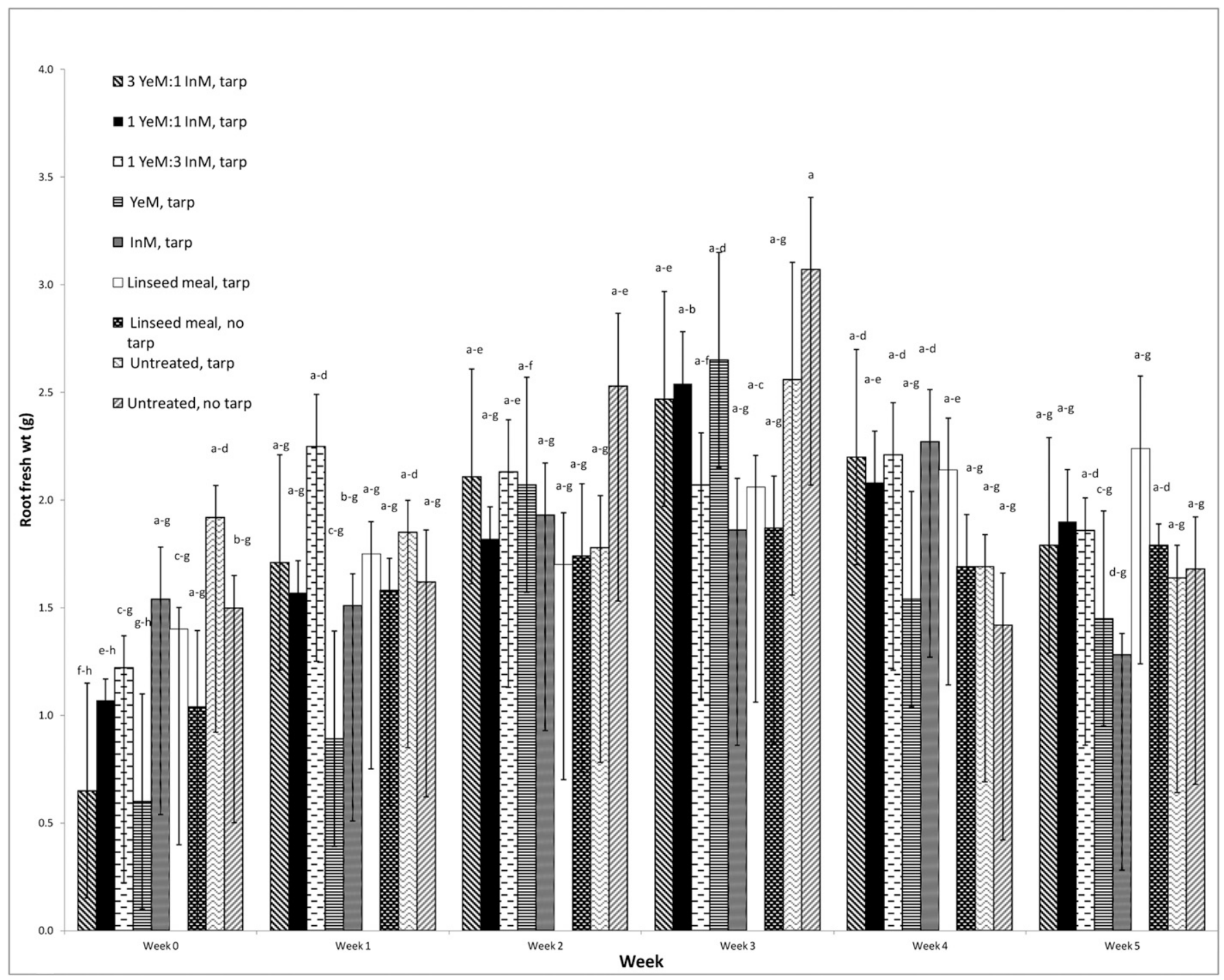

Fig. 1. Root fresh weights of tomato seedlings transplanted into soil amended with seed meals of indian mustard (InM), yellow mustard (YeM), mixtures of these mustard seed meals, linseed meal, or untreated with meal. All amendments were applied at a final total rate of $0.25 \%$ dry weight amendment to weight dry soil. Seed meals were amended into soil and placed in greenhouse pots 0 to 5 weeks before transplant of tomato seedlings. The plants were harvested 2 weeks after transplant to determine if there was initial phytotoxicity to young seedlings. All mustard seed meal treatments were covered with black plastic tarp. Two trials were combined for analysis, with five replicates per trial $(N=10)$. Pairwise comparison of the combinations was accomplished using a one-way ANOVA with the Sidak adjustment; overall $\alpha=0.05$. Values with the same letter are not significantly different; $1 \mathrm{~g}=0.0353 \mathrm{oz}$.

improved plant growth in the absence of tarp. Shoot fresh weights followed a somewhat similar pattern, with the lowest weights from plants grown in untreated soil and without tarp, \pm $\mathrm{RKN}$; weights were decreased by $29.7 \%$ and $54.0 \%$, respectively, compared with the highest weight.

The results were different in Trial 2 (Table 1). Shoot lengths and weights were greatest in plants grown in soil amended with InM seed meal. Shoot lengths were shortest in plants grown in pots with no tarp and no RKN (21.2\% to $21.8 \%$ shorter), and shoot weights were lowest in plants grown in pots with no tarp, untreated soil and no nematodes $(43.7 \%$ decrease in weight compared with the heaviest shoots in InM treatment). Overall, the trend was for lowest shoot vigor in plants grown in pots with untreated soil and no tarp, although there was not always a significant decrease compared with other treatments. This was also the case with root weights. Root fresh weights were lowest in both trials from plants in untreated soil with no RKN and no tarp on the pots; decreases were $45.8 \%$ and $57.1 \%$ compared with the heaviest roots in Trials 1 and 2 , respectively.
High gall indices were recorded from the control plants in untreated soil, with or without tarp on the pots (Table 1). In Trial 1 , all other treatments had lower numbers, except the tarped linseed meal treatments. Overall, the lowest numbers of galls were on plants in soil that received the mustard seed meal treatments, particularly the combinations 1 YeM:1 InM and 1 YeM:3 InM. In Trial 2, the lowest gall indices were from plants treated with YeM and 3 YeM:I InM. In general, the highest numbers of RKN eggs per gram root were recorded from the untreated controls (Fig. 2). 
Table 1. 'BHN444' tomato shoot lengths and weights, root weights, and root galling caused by southern root-knot nematode (RKN) on plants grown in soil amended with seed meals of indian mustard (InM), yellow mustard (YeM), mixtures of these mustard seed meals, or linseed meal in the greenhouse. ${ }^{\mathrm{z}}$

\begin{tabular}{|c|c|c|c|c|c|c|c|c|}
\hline \multirow[b]{2}{*}{ Treatment $^{\mathrm{y}}$} & \multicolumn{2}{|c|}{ Shoot length $(\mathrm{cm})^{x}$} & \multicolumn{2}{|c|}{ Shoot fresh wt $(g)^{x}$} & \multicolumn{2}{|c|}{ Root fresh wt (g) } & \multicolumn{2}{|c|}{ Root galling index } \\
\hline & Trial 1 & Trial 2 & Trial 1 & Trial 2 & Trial 1 & Trial 2 & Trial 1 & Trial 2 \\
\hline \multicolumn{9}{|l|}{ RKN } \\
\hline Untreated, tarp & $27.1 \mathrm{a}$ & $31.7 \mathrm{ab}$ & $16.7 \mathrm{abc}$ & $15.1 \mathrm{ab}$ & $8.6 \mathrm{abc}$ & $5.6 \mathrm{a}$ & $23.1 \mathrm{a}$ & $9.4 \mathrm{a}$ \\
\hline Linseed meal, no tarp & $23.2 \mathrm{ab}$ & $29.5 \mathrm{ab}$ & $17.3 \mathrm{abc}$ & $15.3 \mathrm{ab}$ & $8.9 \mathrm{abc}$ & $7.0 \mathrm{a}$ & $10.8 \mathrm{bc}$ & $11.3 \mathrm{a}$ \\
\hline Linseed meal, tarp & $25.2 \mathrm{ab}$ & $29.8 \mathrm{ab}$ & $18.4 \mathrm{a}$ & $16.2 \mathrm{ab}$ & $9.9 \mathrm{ab}$ & $6.5 \mathrm{a}$ & $13.8 \mathrm{ab}$ & $9.4 \mathrm{a}$ \\
\hline 3 YeM:1 InM, tarp & $24.0 \mathrm{ab}$ & $32.6 \mathrm{ab}$ & $18.6 \mathrm{a}$ & $15.4 \mathrm{ab}$ & $9.4 \mathrm{ab}$ & $5.1 \mathrm{ab}$ & $7.0 \mathrm{bcd}$ & $3.0 \mathrm{c}$ \\
\hline 1 YeM:1 InM, tarp & $25.8 \mathrm{ab}$ & $30.1 \mathrm{ab}$ & $18.2 \mathrm{a}$ & $16.1 \mathrm{ab}$ & $10.7 \mathrm{a}$ & $6.7 \mathrm{a}$ & $3.5 \mathrm{~cd}$ & $5.6 \mathrm{ab}$ \\
\hline 1 YeM:3 InM, tarp & $24.9 \mathrm{ab}$ & $30.3 \mathrm{ab}$ & $16.2 \mathrm{abc}$ & $15.1 \mathrm{ab}$ & $9.0 \mathrm{abc}$ & $5.5 \mathrm{ab}$ & $3.0 \mathrm{~d}$ & $5.6 \mathrm{ab}$ \\
\hline \multicolumn{9}{|l|}{ No RKN } \\
\hline Untreated, no tarp & $16.4 \mathrm{c}$ & $27.1 \mathrm{~b}$ & $8.7 \mathrm{~d}$ & $9.4 \mathrm{c}$ & $5.8 \mathrm{c}$ & $3.0 \mathrm{~b}$ & $\mathrm{NA}^{\mathrm{u}}$ & NA \\
\hline
\end{tabular}

${ }^{z}$ Root galling indices were $\log _{10}(x+1)$-transformed before analysis. Data presented are nontransformed means. All other treatments were not transformed for analysis. Values are means of eight replicates per trial.

yAll amendments were applied at a final total rate of $0.25 \%$ dry weight seed meal to dry weight soil. Soils were amended 2 weeks before transplant. Pots were either covered with black plastic tarp or were not tarped.

${ }^{\mathrm{x}} \mathrm{l} \mathrm{cm}=0.3937$ inch, $1 \mathrm{~g}=0.0353 \mathrm{oz}$.

${ }^{\mathrm{w}} 0=$ no galls, $1=$ less than 5 galls, $5=5$ to 25 galls, $10=26$ to 100 galls, $25=$ more than 100 galls (Daulton and Nusbaum, 1961 ).

"Within a column, values followed by the same letter are not significantly different $(P \leq 0.05)$ according to Tukey's adjustment for multiple comparisons. Significance letters are not comparable among columns.

"Not applicable.

The lowest numbers of RKN eggs per gram root tended to be recovered from plants that were grown in mustard seed meal treatments, although only InM (Trial l) and 3 YeM:1 InM (Trial 2) had population densities lower than the linseed meal controls. These two treatments resulted in 99.4\% (InM) and 92.6\% (3 YeM:1 InM) suppression of RKN population numbers, compared with the highest numbers recorded from each trial (1283 and 2347, respectively).

Field studies. Effects of the mustard seed meal treatments on root weights and nematode densities varied between 2012 and 2013, and also with time during 2012 (Table 2). In 2012 , preplant J2 population densities were not recorded because the field was not naturally infested with RKN. In midseason (August) 2012 (Table 2), there were no differences among treatments in root fresh weights or densities of RKN eggs per gram root. By harvest of 2012 (October), there were differences in root dry weights and in RKN eggs per gram root. Roots from plants in beds amended with 1 YeM:1 InM high rate were $33.3 \%$ to $39.1 \%$ lower in dry weight than roots from the fertilizer only, YeM high rate and InM high rate treatments. No other treatment adversely affected root weights. The highest densities of RKN eggs per gram root recorded at harvest were from the 1 YeM:3 InM high rate treatment. The lowest numbers of RKN eggs per gram root were from beds amended with InM high rate, YeM low rate, and 3 YeM:I InM high rate. These treatments suppressed nematode egg numbers by $68.7 \%$, $69.4 \%$, and $75.6 \%$, respectively, compared with the 1 YeM:3 InM treatment. The same three treatments that suppressed egg numbers on roots also had low densities of $\mathrm{J} 2$ in the soil, although none of the differences were significant. Densities of RKN J2 per $100 \mathrm{~g}$ soil were low preplant and midseason in 2013, ranging from 0 to $11 \mathrm{~J} 2$ per $100 \mathrm{~g}$ soil (May), and 0 to $6 \mathrm{~J} 2$ per $100 \mathrm{~g}$ soil (July). No significant differences among treatments were recorded for any of the measured parameters in 2013 (Table 2).

In 2012, significant differences among treatments were found in numbers of marketable tomato fruit (October; Table 3). Highest tomato fruit numbers were recorded from plants amended with YeM low rate, and lowest numbers from plants in beds amended with 3 YeM:1 InM high rate. Numbers of fruit from the YeM low rate treatment were nearly double the numbers from the 3 YeM:1 InM treatment. Both of these treatments had low nematode numbers at harvest (Table 2). There were no significant differences in tomato fruit weights among the other treatments. However, the general trend was that YeM at both high and low rates resulted in the highest fruit numbers and weights.

At the 2013 harvest (August and September), aboveground plant heights and weights were measured; no significant differences were found among treatments (data not shown). In addition, no significant differences were recorded among treatments in numbers or weights of marketable tomato fruit (Table 3). Amendment with finely ground InM seed meal did not result in increased plant vigor or decreased $\mathrm{RKN}$ population densities (Tables 2 and 3).

WEED POPULATIONS AND FUNGAL AND BACTERIAL PLANT DISEASES IN THE FIELD. Due to lack of treatment by year interaction, weed data were combined over both years. Carpetweed was the most prevalent weed species, accounting for over $70 \%$ of the weeds 


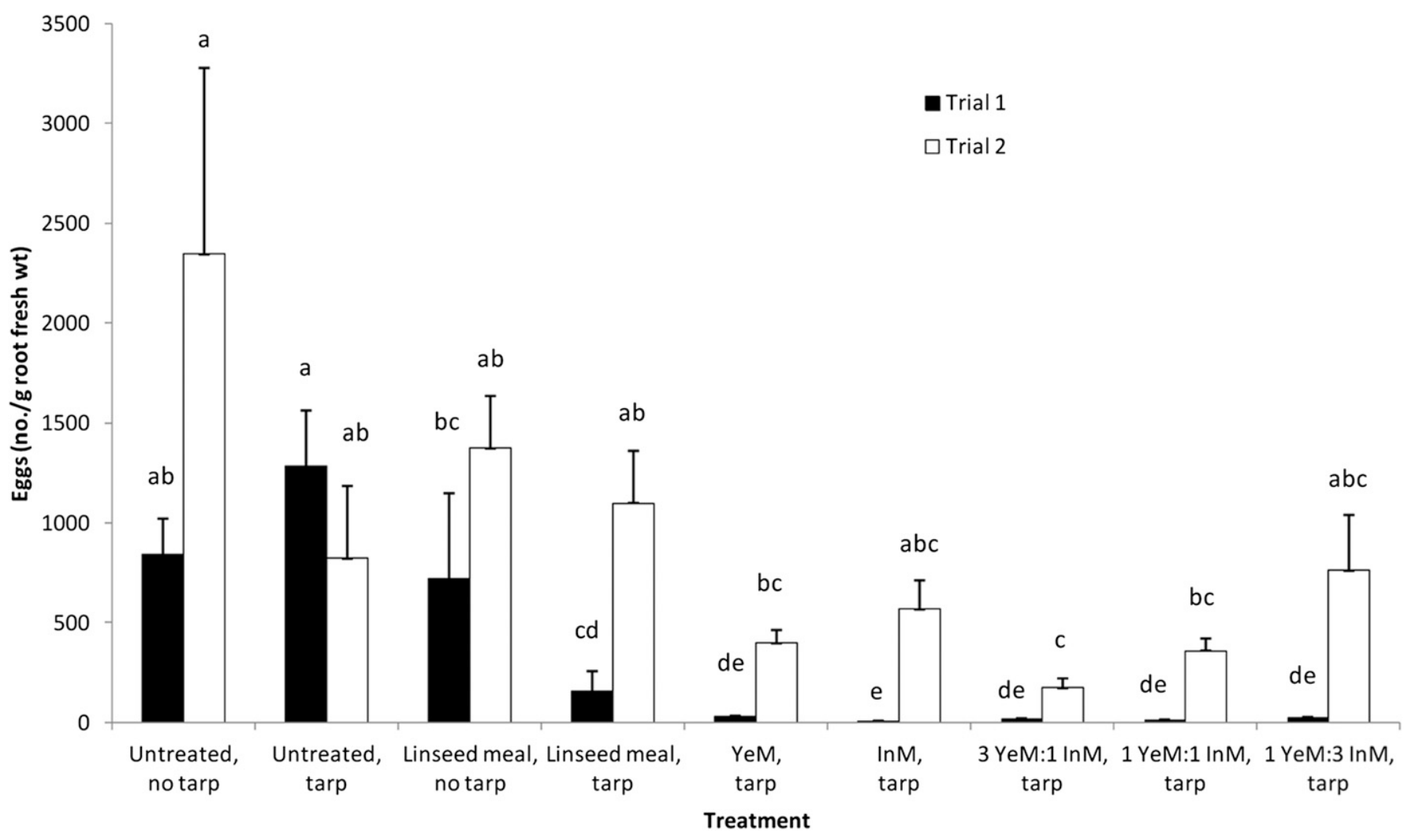

Fig. 2. Southern root-knot nematode eggs per gram root on tomato plants transplanted into soil amended with seed meals of indian mustard (InM), yellow mustard (YeM), mixtures of these mustard seed meals, linseed meal, or untreated with meal. All amendments were applied at a final total rate of $0.25 \%$ dry weight amendment to dry weight soil. Seed meals were amended into soil and placed in greenhouse pots 2 weeks before transplant of tomato seedlings. The plants were harvested 5 weeks after transplant. Tarp was black plastic. Data were $\log 10(x+1)$-transformed before analysis. Data presented are nontransformed means. Values are means of eight replicates per trial. Values with the same letter are not significantly different $(P \leq 0.05)$ according to Tukey's adjustment for multiple comparisons; $1 \mathrm{egg} / \mathrm{g}=28.3495 \mathrm{eggs} / \mathrm{oz}$.

counted (Table 4). There were no treatment differences for any of the weeds present. Septoria leaf spot (2012 and 2013) and bacterial spot (2013) were observed in the experiment. However, disease onset was late in both years, and severity did not exceed $2 \%$ before the end of harvest.

\section{Discussion}

We studied integration of mustard seed meals into a tomato production system with a three-phase approach. First, we determined the amount of time necessary post mustard seed meal amendment to avoid phytotoxicity to tomato. Second, we investigated types and rates of mustard seed meals needed to suppress $\mathrm{RKN}$; phases 1 and 2 were conducted in a greenhouse. Finally, we extended this information to the field to determine if the mustard seed meals (at the tested rates) could be used to suppress nematodes, weeds and diseases while maintaining tomato plant productivity. Across experiments there were some trends. Application of InM seed meal and 3 YeM:1 InM resulted in low numbers of RKN eggs per gram root in one of two greenhouse trials for each treatment, and in the 2012 field study. However, the lack of effects on RKN populations in 2013 demonstrates the challenge of observing consistency across years in the field when implementing mustard seed meals for the suppression of soilborne pests and pathogens.

The two seed meals used in our current study differ in glucosinolate content. The primary glucosinolates are sinalbin (glucosinalbin: 4-hydroxybenzyl glucosinolate) in YeM, and sinigrin (2-propenyl glucosinolate) in InM. The glucosinolates in YeM seed meal degrade to ionic thiocyanate $\left(\mathrm{SCN}^{-}\right)$and other isothiocyanates; sinigrin degrades to form isothiocyanates such as allyl isothiocyanate (ITC), but not $\mathrm{SCN}^{-}$(Borek and Morra, 2005; Buskov et al., 2002; Donkin et al., 1995; Hansson et al., 2008;
Vaughn et al., 2006). The isothiocyanates can be directly toxic to some organisms, and act as biofumigants in the soil (Gimsing and Kirkegaard, 2009). For example, $\mathrm{SCN}^{-}$killed or suppressed germination of a number of plants, including the crop plants carrot, corn (Zea mays), pea (Pisum satipum), and wheat (Triticum aestivum) (Hansson et al., 2008; Harvey, 1931). Ionic thiocyanate and other ITCs are also active against nematodes (Buskov et al., 2002; Donkin et al., 1995; Lazzeri et al., 1993, 2004; Masler et al., 2010; Zasada and Ferris, 2003). Addition of mustard seed meals can also affect other organisms and suppress plant diseases by altering available nitrogen and bacterial communities in the soil (Hollister et al., 2013; Reardon et al., 2013; Weerakoon et al., 2012).

Given the phytotoxicity of these amendments, studies on sensitivity of crop plants are needed to determine optimal timing and rates of seed meal application, as effects vary among 


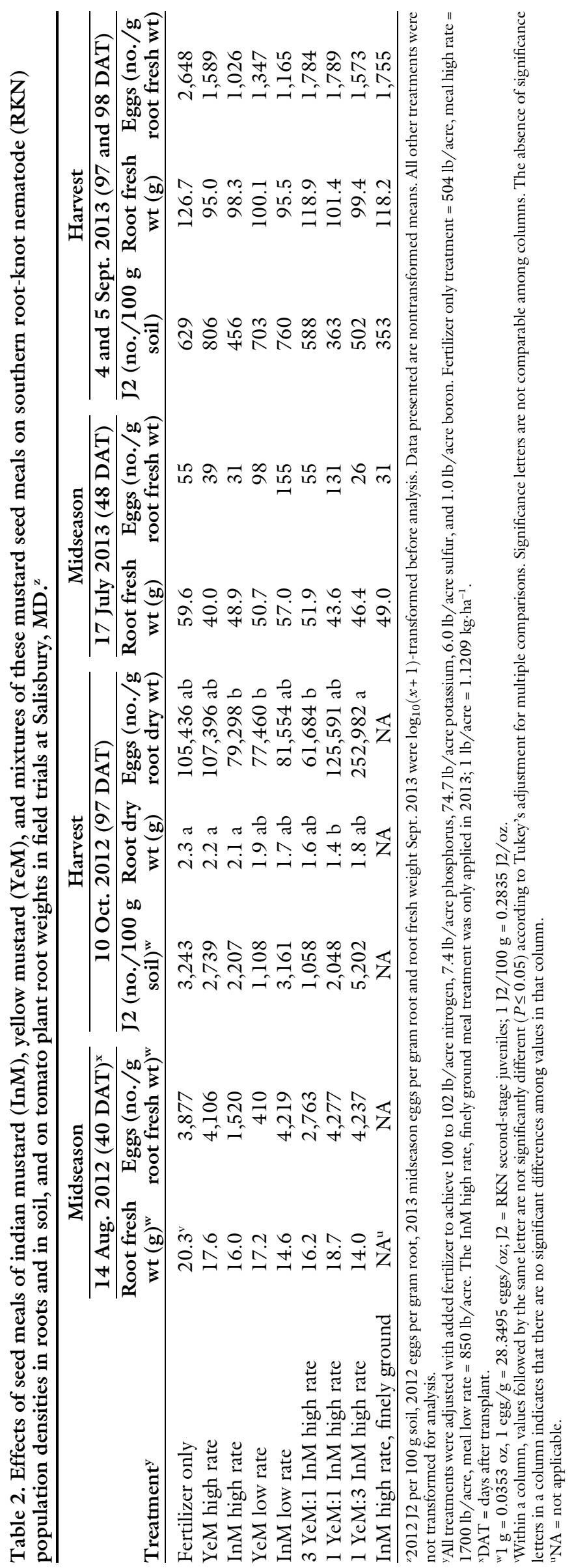

plant species and with the conditions of the application. In our study on phytotoxicity to tomato, the mustard seed meal treatments that resulted in $40 \%$ to $60 \%$ decreases in tomato plant stand all contained YeM seed meal, applied immediately before transplant. The YeM amendment had less effect on plant stand at Week 1 . In previous experiments with the same seed meal types, a higher rate of YeM $(0.5 \%)$ than that used in the current study resulted in $100 \%$ pepper seedling death at Weeks 0 and 1 (Meyer et al., 2011). In the same study, InM was applied at $0.2 \%$, and resulted in $100 \%$ plant death at Week 0 ; this phytotoxicity was not observed in our tomato study. The YeM:InM mixtures were also applied at total rates of $0.5 \%$ to soil and resulted in $100 \%$ plant death at Week 0 . In other research with tomato and pepper, $0.5 \%$ YeM, InM or rapeseed meals were applied to soil $3 \mathrm{~d}$ before planting. All treatments reduced seedling emergence, with YeM exhibiting the greatest phytotoxicity; $63.7 \%$ and $89.1 \%$ reductions in tomato and pepper seedling emergence, respectively, compared with the nonamended controls (Handiseni et al., 2012). These studies combined indicate that $\mathrm{YeM}$ is more toxic than InM to tomato, and likely to pepper as well. Because of the results from our phytotoxicity study, amendments were applied 2 weeks before tomato transplant in the subsequent greenhouse and field studies.

Some of the mustard seed meals suppressed RKN populations on tomato in the greenhouse, compared with numbers from untreated soil. In particular, the 3 YeM:I InM treatment consistently resulted in lower RKN populations than the untreated controls, although there were no significant differences in numbers of eggs per gram root among mustard seed meal treatments. In previous research with pepper, there was a tendency for InM seed meal at some application rates to be more effective than YeM seed meal at suppressing $\mathrm{RKN}$ on pepper, and combination treatments were also effective (Meyer et al., 2011). InM seed meal was also more nematotoxic than YeM seed meal in an earlier study; $0.5 \%$ InM prevented recovery of RKN from amended soil, while YeM seed meal needed to be added at $2.5 \%$ or more 
Table 3. Effects of seed meals of indian mustard (InM), yellow mustard (YeM), and mixtures of these mustard seed meals on tomato fruit yields at harvest in field trials at Salisbury, MD. ${ }^{\mathrm{z}}$

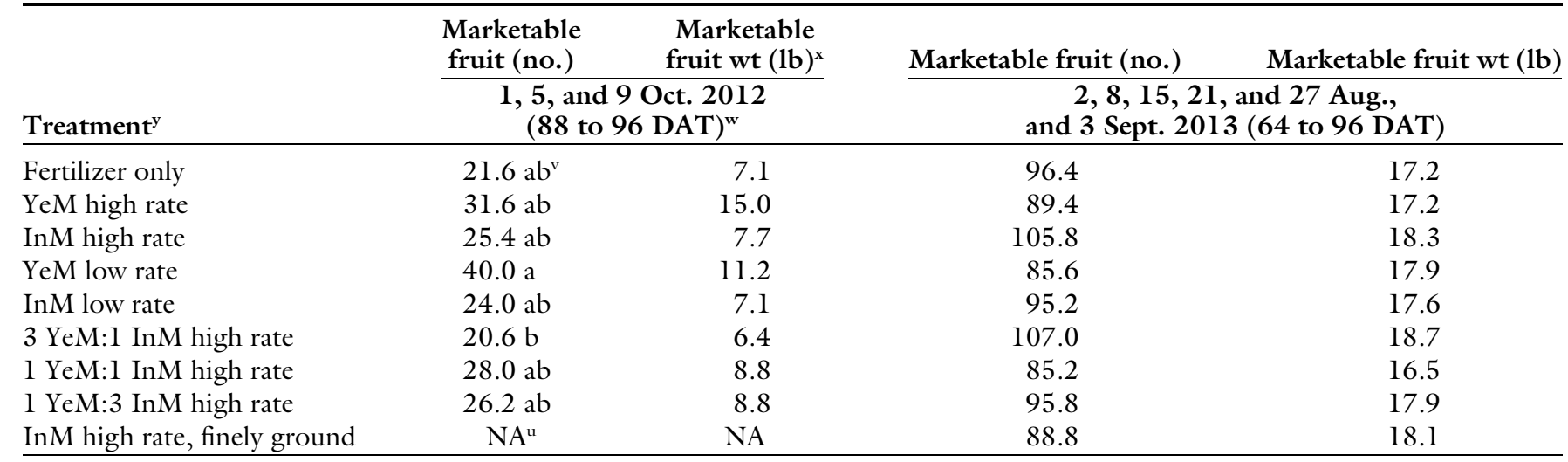

${ }^{\mathrm{z}} 2012$ fruit weights were $\log 10(x+1)$-transformed before analysis. Data presented are nontransformed means. Fruit numbers and 2013 fruit weights were not transformed for analysis. Results are means of three plants per plot.

yAll treatments were adjusted with added fertilizer to achieve 100 to $102 \mathrm{lb} /$ acre nitrogen, $7.4 \mathrm{lb} / \mathrm{acre}$ phosphorus, $74.7 \mathrm{lb} / \mathrm{acre}$ potassium, $6.0 \mathrm{lb} / \mathrm{acre}$ sulfur, and $1.0 \mathrm{lb} / \mathrm{acre}$ boron. Fertilizer only treatment $=504 \mathrm{lb} /$ acre, meal high rate $=1700 \mathrm{lb} /$ acre, meal low rate $=850 \mathrm{lb} /$ acre. The InM high rate, finely ground meal treatment was only applied in $2013 ; \mathrm{lb} /$ acre $=1.1209 \mathrm{~kg} \cdot \mathrm{ha}^{-1}$.

${ }^{\mathrm{x}} \mathrm{l} \mathrm{lb}=0.4536 \mathrm{~kg}$.

wDAT $=$ days after transplant

"Within a column, values followed by the same letter are not significantly different $(P \leq 0.05)$ according to Tukey's adjustment for multiple comparisons. Significance letters are not comparable among columns. The absence of significance letters in a column indicates that there are no significant differences among values in that column.

${ }^{u} \mathrm{NA}=$ not applicable.

Table 4. Effects of seed meals of indian mustard (InM), yellow mustard (YeM), and mixtures of these mustard seed meals on weed population densities in tomato beds in field trials at Salisbury, MD, in 2012 and $2013 .^{2}$

\begin{tabular}{lccc}
\hline & Carpetweed & Total grasses & Total weeds \\
\cline { 2 - 4 } Treatment $^{\mathbf{y}}$ & \multicolumn{3}{c}{ Weeds $\left(\mathbf{n o .} / \mathbf{f t}^{\mathbf{2}}\right)^{\mathbf{x}}$} \\
\hline Fertilizer only & 39 & 4 & 53 \\
YeM high rate & 41 & 4 & 51 \\
InM high rate & 36 & 3 & 46 \\
YeM low rate & 47 & 3 & 60 \\
InM low rate & 43 & 4 & 55 \\
3 YeM:1 InM high rate & 35 & 4 & 44 \\
I YeM:1 InM high rate & 34 & 3 & 44 \\
I YeM:3 InM high rate & 35 & 3 & 44 \\
InM high rate, finely ground & 53 & 6 & 63 \\
\hline
\end{tabular}

${ }^{2}$ Weed counts were $\log (x+0.1)$-transformed before analysis. Data presented are nontransformed means. There are no significant differences among the values in any column

yAll treatments were adjusted with added fertilizer to achieve 100 to $102 \mathrm{lb} /$ acre nitrogen, $7.4 \mathrm{lb} / \mathrm{acre}$ phosphorus, $74.7 \mathrm{lb} /$ acre potassium, $6.0 \mathrm{lb} /$ acre sulfur, and $1.0 \mathrm{lb} /$ acre boron. Fertilizer only treatment $=504$ $\mathrm{lb} /$ acre, meal high rate $=1700 \mathrm{lb} / \mathrm{acre}$, meal low rate $=850 \mathrm{lb} /$ acre, $\mathrm{l} \mathrm{lb}=0.4536 \mathrm{~kg}$. The InM high rate, finely ground meal treatment was only applied in $2013 ; \mathrm{llb} /$ acre $=1.1209 \mathrm{~kg} \cdot \mathrm{ha}^{-1}$.

${ }^{x} 1$ weed $/ \mathrm{ft}^{2}=10.7639$ weeds $/ \mathrm{m}^{2}$.

(Zasada et al., 2009). However, the glucosinolate in YeM does produce 4-OH benzyl alcohol, which has some nematicidal activity (Buskov et al., 2002). Several factors could account for inconsistent results among studies, including soil type, use of pasteurized/ steamed soil vs. unpasteurized soil, and rates of meal application. In the current study on tomato, field soil was used for the greenhouse experiments, rather than pasteurized soil, so it is possible that effects on the resident microbial community altered the activity of mustard seed meals against
RKN compared with the earlier research with these same meals and pepper.

In the 2-year field study, effects of the mustard seed meal treatments on tomato plant yields and RKN population densities were not consistent between years. In 2012, InM seed meal at the high rate resulted in low numbers of $\mathrm{RKN}$ eggs per gram root at harvest, and it was expected that mixtures containing high amounts of InM would also suppress nematode populations. However, low RKN eggs per gram root were recorded from 3
YeM:1 InM (high rate) and YeM (low rate) treatments. Application of YeM (low rate) also resulted in high tomato fruit numbers in 2012. These results were not repeated in 2013; there were no differences among treatments in RKN populations, plant vigor, or fruit yields. Weed population numbers were unaffected by any treatment in the 2012 or 2013 field studies, despite many reports of weed control with mustard seed meals (Brown and Morra, 2005; Hansson et al., 2008; Rothlisberger et al., 2012; Vaughn et al., 2006).

Meal particle size did not enhance activity of InM. Reports on effects of particle size have varied. Previous studies on YeM indicated that a fine flake increased activity against the root-lesion nematode [cobb's meadow nematode (Pratylenchus penetrans)], compared with a larger flake or pellet (Zasada et al., 2009), and making a powder of rapeseed seed meal suppressed root rot caused by Pythium compared with a flake application (Cohen and Mazzola, 2006). Seed meal of InM in a fine particle size was effective against apple root infection (root rot) caused by Rhizoctonia solani, while coarse particle size was not effective; however, size was not a factor in suppressing root-lesion nematode or root rot caused by Pythium sp. (Mazzola and Zhao, 2010). 


\section{Conclusion}

At the tested rates, none of the mustard seed meal treatments were consistently efficacious for enhancing plant vigor or suppressing plant pathogens. Differences in activity between years may have resulted from spatial variation in nematode numbers across the naturally infested field in 2013, differing soil types, variations in microclimate in the two fields, and the possibility that the two fields might not have received the same amounts of water each year after beds were prepared. The mustard seed meal amendment rates used in our study were selected to see if they would be effective while minimizing costs and keeping nitrogen levels low. The field study indicated that low amendment rates of YeM may suppress RKN populations and result in higher fruit yields, but the results were inconsistent, and weed numbers were unaffected by the tested rates.

\section{Literature cited}

Borek, V. and M.J. Morra. 2005. Ionic thiocyanate $\left(\mathrm{SCN}^{-}\right)$production from 4-hydroxybenzyl glucosinolate contained in Sinapis alba seed meal. J. Agr. Food Chem. 53:8650-8654.

Brown, J. and M.J. Morra. 2005. Glucosinolate-containing seed meal as a soil amendment to control plant pests 20002002. Natl. Renewable Energy Lab. Subcontract Rpt. NREL/SR-510-35254. 22 Dec. 2014. <http://www.nrel.gov/ docs/fy05osti/35254.pdf>.

Buskov, S., B. Serra, E. Rosa, H. Sørensen, and J.C. Sørensen. 2002. Effects of intact glucosinolates and products produced from glucosinolates in myrosinase-catalyzed hydrolysis on the potato cyst nematode (Globodera rostochiensis cv. Woll). J. Agr. Food Chem. 50:690-695.

Cohen, M.F. and M. Mazzola. 2006. Resident bacteria, nitric oxide emission and particle size modulate the effect of Brassica napus seed meal on disease incited by Rhizoctonia solani and Pythium spp. Plant Soil 286:75-86.

Daulton, R.A.C. and C.J. Nusbaum. 1961. The effect of soil temperature on the survival of the root-knot nematodes Meloidogyne javanica and M. hapla. Nematologica 6:280-294.

Donkin, S.G., M.A. Eiteman, and P.L. Williams. 1995. Toxicity of glucosinolates and their enzymatic decomposition products to Caenorbabditis elegans. J. Nematol. $27: 258-262$.
Gigot, A.J., I.A. Zasada, and T.W. Walters 2013. Integration of brassicaceous seed meals into red raspberry production systems. Appl. Soil Ecol. 64:23-31.

Gimsing, A.L. and J.A. Kirkegaard. 2009. Glucosinolates and biofumigation: Fate of glucosinolates and their hydrolysis products in soil. Phytochem. Rev. 8:299-310.

Handiseni, M., J. Brown, R. Zemetra, and M. Mazzola. 2012. Use of brassicaceous seed meals to improve seedling emergence of tomato and pepper in Pythium ultimum infested soils. Arch. Phytopathol. Plant Protection 45:12041209.

Hansson, D., M.J. Morra, V. Borek, A.J. Snyder, J.L. Johnson-Maynard, and D.C. Thill. 2008. Ionic thiocyanate $\left(\mathrm{SCN}^{-}\right)$ production, fate, and phytotoxicity in soil amended with Brassicaceae seed meals. J. Agr. Food Chem. 56:3912-3917.

Harvey, R.B. 1931. Ammonium thiocyanate as a weed eradicant. Agron. J. 23:944-946.

Henderson, D.R., E. Riga, R.A. Ramirez, J. Wilson, and W.E. Snyder. 2009. Mustard biofumigation disrupts biological control by Steinernema spp. nematodes in the soil. Biol. Control 48:316-322.

Hollister, E.B., P. Hu, A.S. Wang, F.M. Hons, and T.J. Gentry. 2013. Differential impacts of brassicaceous and nonbrassicaceous oilseed meals on soil bacterial and fungal communities. FEMS Microbiol. Ecol. 83:632-641

Hooper, D.J. 1986. Extraction of freeliving stages from soil, p. 5-30. In: J.F. Southey (ed.). Laboratory methods for work with plant and soil nematodes. Ministry Agr. Fisheries Food Reference Book 402. London, UK.

Lazzeri, L., G. Curto, E. Dallavalle, L. D'Avino, L. Malaguti, R. Santi, and G. Patalano. 2009. Nematicidal efficacy of biofumigation by defatted Brassicaceae meal for control of Meloidogyne incognita (Kofoid et White) Chitw. on a full field zucchini crop. J. Sustain. Agr. 33:349358.

Lazzeri, L., G. Curto, O. Leoni, and E. Dallavalle. 2004. Effects of glucosinolates and their enzymatic hydrolysis products via myrosinase on the root-knot nematode Meloidogyne incognita (Kofoid et White). Chitw. J. Agr. Food Chem. 52:6703-6707.

Lazzeri, L., R. Tacconi, and S. Palmieri. 1993. In vitro activity of some glucosinolates and their reaction products toward a population of the nematode Heterodera schachtii. J. Agr. Food Chem. 41:825829.
Masler, E.P., I.A. Zasada, S. Sardanelli, S.T. Rogers, and J.M. Halbrendt. 2010. Effects of benzyl isothiocyanate on the reproduction of Meloidogyne incognita on Glycine max and Capsicum annuum. Nematology 12:693-699.

Mazzola, M. and J. Brown. 2010. Efficacy of brassicaceous seed meal formulations for the control of apple replant disease in conventional and organic production systems. Plant Dis. 94:835-842.

Mazzola, M., J. Brown, A.D. Izzo, and M.F. Cohen. 2007. Mechanism of action and efficacy of seed meal-induced pathogen suppression differ in a Brassicaceae species and time-dependent manner. Phytopathology 97:454-460.

Mazzola, M. and S.L. Straus. 2014. Replant disease control and system resilience to pathogen re-infestation in response to Brassica seed meal amendment. Acta Hort. 1044:105-112.

Mazzola, M. and X. Zhao. 2010. Brassica juncea seed meal particle size influences chemistry but not biology-based suppression of individual agents inciting apple replant disease. Plant Soil 337:313-324.

Meyer, S.L.F., I.A. Zasada, S.B. Orisajo, and M.J. Morra. 2011. Mustard seed meal mixtures: Management of Meloidogyne incognita on pepper and potential phytotoxicity. J. Nematol. 43:7-15.

Popova, I. and M.J. Morra. 2014. Sinigrin and sinalbin quantification in mustard seed using high performance liquid chromatography-time-of-flight mass spectrometry. J. Food Compos. Anal. 35: 120-126.

Rahman, L. and T. Somers. 2005. Suppression of root knot nematode (Meloidogyne javanica) after incorporation of Indian mustard cv. Nemfix as green manure and seed meal in vineyards. Australas. Plant Pathol. 34:77-83.

Reardon, C.L., S.L. Strauss, and M. Mazzola. 2013. Changes in available nitrogen and nematode abundance in response to Brassica seed meal amendment of orchard soil. Soil Biol. Biochem. $57: 22-29$.

Rothlisberger, K.L., F.M. Hons, T.J. Gentry, and S.A. Senseman. 2012. Oilseed meal effects on emergence and survival of crop and weed species. Appl. Environ. Soil Sci. 2012:1-10.

Snyder, A., M.J. Morra, J. JohnsonMaynard, and D.C. Thill. 2009. Seed meals from Brassicaceae oilseed crops as soil amendments: Influence on carrot growth, microbial biomass, nitrogen, and nitrogen mineralization. HortScience $44: 354-361$ 


\section{Research Reports}

Vaughn, S.F., D.E. Palmquist, S.M. Duval, and M.A. Berhow. 2006. Herbicidal activity of glucosinolate-containing seedmeals. Weed Sci. 54:743-748.

Weerakoon, D.M.N., C.L. Reardon, T.C. Paulitz, A.D. Izzo, and M. Mazzola. 2012. Long-term suppression of Pythium abappressorium induced by
Brassica juncea seed meal amendment is biologically mediated. Soil Biol. Biochem. 51:44-52.

Zasada, I.A. and H. Ferris. 2003. Sensitivity of Meloidogyne javanica and Tylenchulus semipenetrans to isothiocyanates in laboratory assays. Phytopathology 93:747-750.
Zasada, I.A., S.L.F. Meyer, and M.J. Morra. 2009. Brassicaceous seed meals as soil amendments to suppress the plant-parasitic nematodes Pratylenchus penetrans and Meloidogyne incognita. J. Nematol. 41:221-227. 